\title{
Assessing canal seepage and soil salinity using the electromagnetic remote sensing technology
}

\author{
F. Cassel S. \& D. Zoldoske \\ Center for Irrigation Technology, California State University, \\ Fresno, CA, USA
}

\begin{abstract}
Canal seepage and soil salinity are two major problems in irrigated areas of California's Central Valley, USA. Seepage is very common throughout the vast network of irrigation canals found in California. Most of these canals are earthen structures, where seepage contributes to the loss of millions of litres of water annually. Salinity problems are attributed to saline parent material, clayey soils, intensive irrigation, shallow water tables, and inadequate drainage that prevents the leaching of soluble salts. Several irrigation management practices, including sequential reuse of drainage waters within farm boundaries, are currently being tested in the region. Such practices are expected to reduce drainage volume, conserve irrigation water, and contribute to soil reclamation. Canal seepage and soil salinity can be assessed very accurately using the electromagnetic (EM) remote sensing technique. When coupled with a GPS and data logging capabilities, a mobilized EM system can provide automated and geo-referenced measurements over large areas. The study objectives were to locate seepage along irrigation canals and assess soil salinity in agricultural fields using the EM approach. Calibration of the EM data was performed following soil sampling. Samples were analyzed for electrical conductivity, texture, and moisture. Surface maps describing spatial distribution of these parameters were generated using GIS. The study suggested that the location of seepage could be detected rapidly and cost-effectively with the EM meter. The salinity assessment survey indicated that soil salinity levels ranged from 1 to $39 \mathrm{dS} / \mathrm{m}$, with high spatial variability observed in most areas. Elevated salinity values were associated with poor drainage management. Growers and water agencies can utilize information from this study to develop water management and conservation strategies.

Keywords: canal seepage, soil salinity, electromagnetic induction, drainage.
\end{abstract}




\section{Introduction}

Seepage from irrigation canals is a serious water management problem in California's San Joaquin Valley, USA. It is estimated that more than 600 million cubic meters of water are being lost every year. Seepage reduces irrigation efficiency and its water may contain toxic substances harmful to soils and ground waters. Additionally, water shortage is becoming a very important problem for California agriculture. Is it is forecasted that, by 2030, California's population will increase to 48 million people and the state will experience water shortages of 1.2 billion $\mathrm{m}^{3}$ in average years and 4.8 billion $\mathrm{m}^{3}$ in drought years [2]. These shortages will inevitably result in water reallocation to urban and industrial sectors, thereby posing a significant threat to the agriculture industry. Thus, it is important to identify tools that can help detect potential seepage along canals, thereby conserving irrigation water and sustaining crop productivity in the region.

High salinity is also a major water quality concern in many irrigated agricultural lands of California. Such salinity condition is attributed to a combination of factors including sedimentary parent material weathering, shallow saline water table $(<3 \mathrm{~m})$, high agricultural water demand, inadequate drainage, and increased canal seepage. Excessive soil salinity can affect crop productivity, soil structure, and water quality. These salinity-related impacts eventually result in soil erosion and land degradation. Approximately 2 million hectares of the state irrigated farmlands are affected by saline soils or saline irrigation water [9]. Salinisation is particularly a threat in the San Joaquin Valley, where the daily net salt inflow into the region during the irrigation season is approximately 1.3 million tons [15]. Managing salinity and improving management of water resources therefore appears essential to sustain land quality and crop production.

Soil salinity is difficult to quantify because of rapid changes over space and time. Traditional measurement methods, such as four-electrode probes and soil sampling, require extensive data collection and laboratory analyses that are very slow, labour-intensive, and expensive [10]. The electromagnetic (EM) induction technique has become a very useful and cost-effective tool to monitor and diagnose soil salinity over large areas, because it allows for rapid and aboveground non-invasive measurements [7]. Additionally, EM sensors generally provide better and faster estimates of soil salinity than direct methods [16]. The EM instrument's transmitter coil induces an electromagnetic field in the ground, which in turn creates a secondary magnetic field that is measured by the receiver coil. The ratio of the primary and secondary electromagnetic fields provides a measure of the depth-weighted apparent electrical conductivity (EC) in a volume of soil below both coils [17]. Along with Global Positioning System data, the EM technique can provide geo-referenced distribution of soil EC (salinity) conditions in vast irrigated areas. Details on electromagnetic induction principles and soil conductivity measurements can be found in McNeill $[11,12]$. Since EC of a soil is a function of its water content, salt content, and texture, the EM technique can also be very valuable for canal seepage assessment. 
Researchers in Australia found the technology was effective for such detections [1]. Therefore, the objectives of this study was to assess seepage along irrigation canals and soil salinity in agricultural fields of Central California using remote sensing approaches, including electromagnetic induction (EM) technique and Global Positioning System (GPS).

\section{Materials and methods}

A Mobile Conductivity Assessment (MCA) system was developed at California State University, Fresno, to conduct extended canal and salinity surveys. The MCA system comprised four basic components mounted on a vehicle: (1) an EM induction sensor, (2) a global positioning system (GPS) receiver, (3) a computer, and (4) a hydraulic soil sampler. The EM sensor was placed in a plastic carriersled attached to the rear of the vehicle. The EM and GPS instruments were connected via digital interfaces to an on-board computer that simultaneously recorded the EM readings along with their geographical locations. Since EM measurements are relative, calibration of the data through soil sampling was necessary to obtain absolute soil moisture and salinity values. Optimal sampling plans were generated using the statistical package ESAP, specially developed to analyze the EM data [8].

\subsection{Canal seepage assessment}

The canal seepage survey was conducted at the Lost Hills Water District in the southern San Joaquin Valley. An unlined section of a canal, about $1200 \mathrm{~m}$ long, was selected for the study. The survey was performed when the canal was open and susceptible to seepage. The soil along the canal was a clay loam with increasing clay content with depth.

The EM and GPS data were recorded from four traverses parallel to water flow on each side of the canal. The survey was conducted at a speed of about 6 $\mathrm{km} / \mathrm{h}$, with readings taken every $2.5 \mathrm{~s}$. The sensor used in this survey was an EM-31 meter (Geonics Limited, Ontario, Canada) that measured soil EC and indirectly moisture down to a depth of $3 \mathrm{~m}$. The EM-31 operates at a frequency of $9.8 \mathrm{kHz}$ and has a fixed inter-coil spacing of $3.7 \mathrm{~m}$.

Optimal sampling plan consisted of six locations characterizing the spatial distribution of EM readings along the canal. At these sites, soil samples were collected in $0.3 \mathrm{~m}$ increments to a depth of $2.7 \mathrm{~m}$ using the hydraulic sampler. Soil water content was determined on these samples, following standard analytical methods [6, 14]. Estimates of soil water content were then obtained for the entire survey area using ESAP. Contour maps showing the soil water distribution down to $2.7 \mathrm{~m}$ were generated with the ArcGIS software [3].

\subsection{Soil salinity assessment}

The soil salinity surveys were conducted in 2004 on a farmland located south of Fresno in the Central San Joaquin Valley. The site was chosen because it served as a leading demonstration project on sequential drainage water reuse for the 
Westside San Joaquin Valley. The soil in the study area is classified as an oxalic silty clay loam with a well-developed salinity profile. The entire farmland is drained with subsurface plastic tiles installed at 2.5 to $3 \mathrm{~m}$ depth and spaced every 80 to $90 \mathrm{~m}$. In this reclamation project, drainage water (DW) is reused three times to irrigate crops of increasing salinity tolerance. Good quality canal water is first used to irrigate high value crops (Area A), fig.1. Then, drainage water collected from A is applied to salt tolerant crops (Area B) and drainage from $B$ is applied to salt tolerant forages (Area $C$ ). Area D receives the highly saline drainage water collected from $C$. Overall benefits of drainage reuse practices are detailed in Grattan and Oster [4], Kaffka et al. [5], and Oster and Grattan [13].

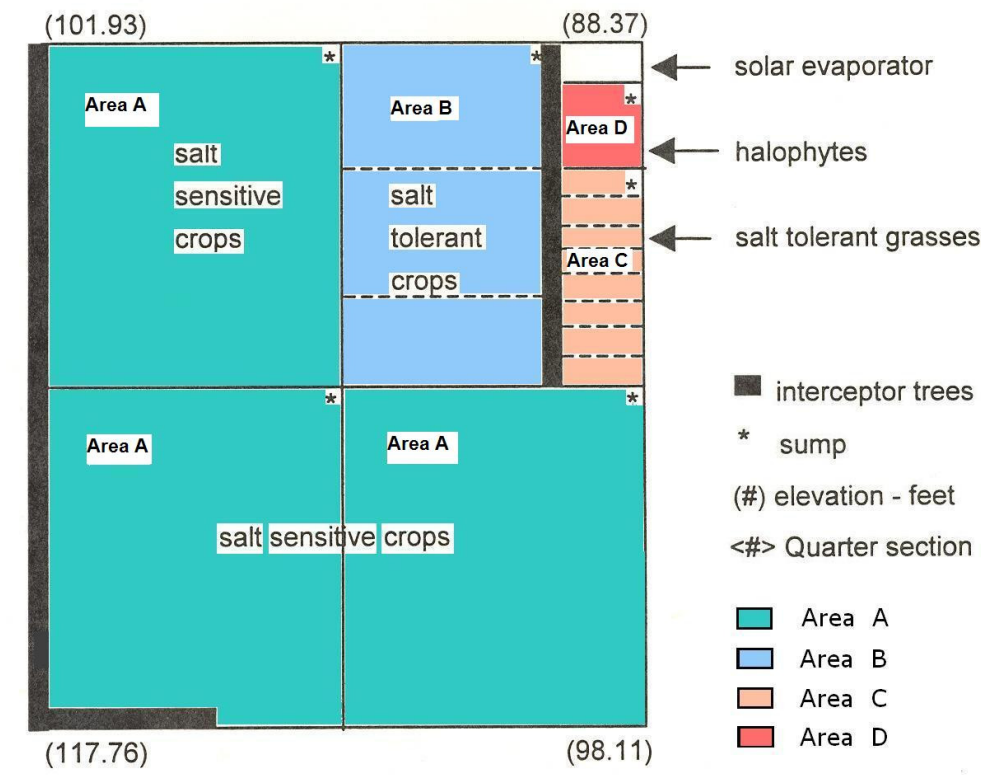

Figure 1: $\quad$ Schematic of drainage reuse system implemented at study site.

The EM measurements were taken in the four areas (A: tomato-wheat, B: grass- wildrye, C: salt tolerant forages- wheatgrass, D: halophytes- saltgrass, salicornia), which successively received reused DW. In each field, the EM and GPS data were collected along transects spaced $24 \mathrm{~m}$ apart; measurements were taken every $12 \mathrm{~m}$ along transects. The EM instrument used in this study was the EM-38 dual dipole. The device was operated in both horizontal and vertical positions at the soil surface to obtain effective measurement depths of $0.9 \mathrm{~m}$ and $1.8 \mathrm{~m}$, respectively. The instrument operates at a frequency of $14.6 \mathrm{kHz}$ and has a fixed inter-coil spacing of $1 \mathrm{~m}$.

Depending on the field size, six or twelve sites characterizing the spatial distribution of EC across each field were selected for calibration. At these sites, soil samples were collected in $0.30 \mathrm{~m}$ increments to a depth of $1.5 \mathrm{~m}$. Electrical 
conductivity (1:1 soil:water extracts), moisture, and saturation percentage were determined on these samples, following standard analytical methods [14]. Soil salinity for the entire survey area was then estimated using ESAP. Contour maps showing the salinity distribution on all fields were generated with ArcGIS [3] using kriging interpolation.

\section{Results and discussion}

\subsection{Canal seepage assessment}

Contour maps showing the soil moisture distribution along the canal at different profile depths are presented in fig. 2 .

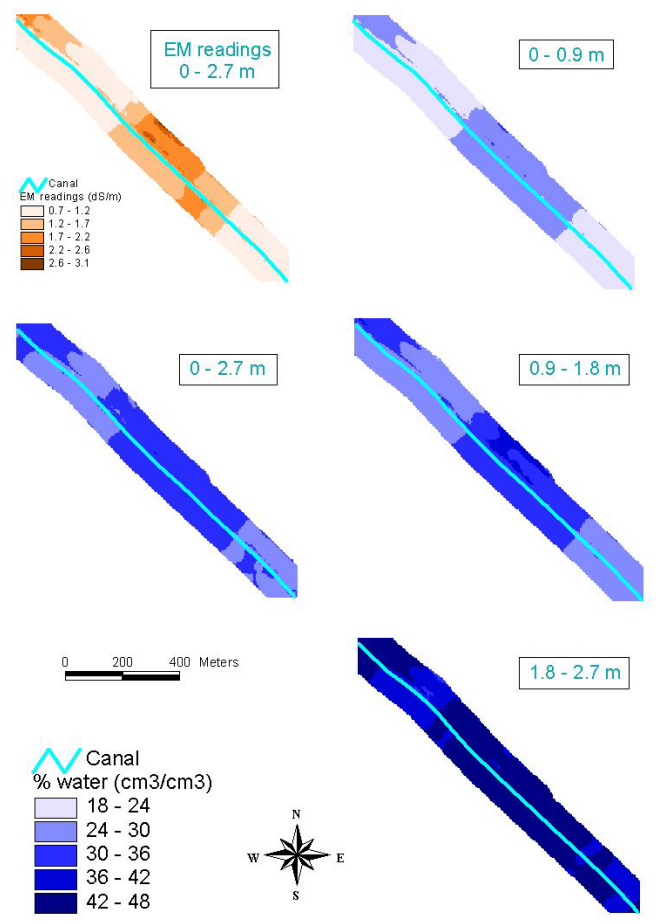

Figure 2: $\quad$ Soil moisture distribution along canal.

The results from the canal seepage survey indicated that soil water content was lowest near the surface $(0-0.9 \mathrm{~m})$ with values ranging from 20 to $30 \%$. The maps also showed that water content increased with depth. The $1.8-2.7 \mathrm{~m}$ profile had the highest moisture levels (up to $48 \mathrm{~cm}^{3} / \mathrm{cm}^{3}$ ) due to the presence of water table at those depths. In the upper soil profile $(0-1.8 \mathrm{~m})$, water content was greater in the mid-section and north-east segment of the canal. Higher soil water content was indicative of potential seepage. Water loss in that section of the 
canal was also observed by the Irrigation District. The overall results of such study and the contour maps can be useful in determining the exact location of seepage as well as improving water management and conservation strategies along irrigation canals.

\subsection{Soil salinity assessment}

The results indicated that the vertical to horizontal EM signal correlations were very high $(\mathrm{r}>0.97)$ in fields covering areas $\mathrm{A}, \mathrm{B}$, and $\mathrm{C}$. Correlations in area D $(r=0.75)$ were lower due to the important variability in salinity observed across the profile depths. In each area, the correlations between measured EC and estimated salinity data were above 0.85 , suggesting a high degree of survey reliability for salinity estimation. Basics statistics on the salinity levels predicted by ESAP across the farmland are presented in Table 1.

Table 1: Statistics of soil salinity data $(\mathrm{dS} / \mathrm{m})$ estimated in all areas of farmland.

\begin{tabular}{|c|c|c|c|c|c|c|}
\hline Area & $\begin{array}{l}\text { Depth } \\
(\mathrm{m})\end{array}$ & Mean & $\begin{array}{l}\text { Standard } \\
\text { deviation }\end{array}$ & Minimum & Maximum & $\mathrm{n}$ \\
\hline \multirow[t]{5}{*}{ A } & $0-0.3$ & 1.77 & 1.00 & 0.38 & 14.0 & 6780 \\
\hline & $0.3-0.6$ & 3.34 & 2.25 & 0.09 & 17.5 & \\
\hline & $0.6-0.9$ & 4.56 & 2.19 & 0.27 & 15.3 & \\
\hline & $0.9-1.2$ & 4.70 & 1.90 & 0.42 & 17.4 & \\
\hline & $1.2-1.5$ & 4.96 & 1.69 & 0.67 & 14.1 & \\
\hline \multirow[t]{5}{*}{$\mathrm{B}$} & $0-0.3$ & 6.34 & 1.17 & 0.34 & 17.8 & 1896 \\
\hline & $0.3-0.6$ & 8.63 & 1.06 & 1.30 & 19.9 & \\
\hline & $0.6-0.9$ & 9.62 & 1.46 & 2.29 & 20.2 & \\
\hline & $0.9-1.2$ & 9.47 & 1.33 & 4.06 & 14.4 & \\
\hline & $1.2-1.5$ & 8.71 & 1.20 & 4.27 & 20.2 & \\
\hline \multirow[t]{5}{*}{$\mathrm{C}$} & $0-0.3$ & 10.4 & 4.23 & 7.52 & 33.8 & 207 \\
\hline & $0.3-0.6$ & 9.42 & 3.01 & 7.28 & 24.8 & \\
\hline & $0.6-0.9$ & 9.70 & 5.62 & 6.14 & 38.6 & \\
\hline & $0.9-1.2$ & 9.14 & 4.46 & 6.32 & 31.8 & \\
\hline & $1.2-1.5$ & 8.12 & 2.63 & 6.29 & 19.6 & \\
\hline \multirow[t]{5}{*}{$\mathrm{D}$} & $0-0.3$ & 15.7 & 0.04 & 15.6 & 15.9 & 130 \\
\hline & $0.3-0.6$ & 16.9 & 0.21 & 16.1 & 17.4 & \\
\hline & $0.6-0.9$ & 15.7 & 0.26 & 15.1 & 16.7 & \\
\hline & $0.9-1.2$ & 14.6 & 0.39 & 13.2 & 15.6 & \\
\hline & $1.2-1.5$ & 10.5 & 0.96 & 7.22 & 13.0 & \\
\hline
\end{tabular}

The mean soil salinity levels in area A ranged from 2 to $5 \mathrm{dS} / \mathrm{m}$ and increased with depth, which is indicative of good drainage management and leaching of salts through the profile. In area B, higher mean salinity was observed (6-10 $\mathrm{dS} / \mathrm{m}$ ), although maximum values were similar to those found in areas A. Mean salinity levels in area $\mathrm{C}$ ranged from 8 to $10 \mathrm{dS} / \mathrm{m}$; however very high values 
were detected in part of the field. Mean soil salinity was highest in area D, ranging from 11 to $17 \mathrm{dS} / \mathrm{m}$, and decreasing with depth. This inverted soil profile was explained by the very high salt concentration in the drainage water applied to that area.

The contour maps representing the average salinity levels in the $0-1.5 \mathrm{~m}$ profile are shown in fig. 3 for the entire surveyed farmland. These maps illustrate the drainage management practices performed on the farm. The lowest salt amounts $(<10 \mathrm{dS} / \mathrm{m})$ were observed in areas A where fresh canal water was applied to the fields, whereas area D which received the third reuse drainage water, exhibited the highest salinity levels $(12-18 \mathrm{dS} / \mathrm{m})$. Salinity levels increased from south to north in area B, indicating that the northern portion is suffering from a more pronounced salinity problem and that the southern part is slowly being reclaimed. Area $\mathrm{C}$ showed high variability in soil salinity (8-18 $\mathrm{dS} / \mathrm{m})$. When compared with maps generated in previous years, soil salinity levels decreased in areas $\mathrm{A}$ and $\mathrm{B}$, suggesting the benefits of the sequential drainage reuse practices.

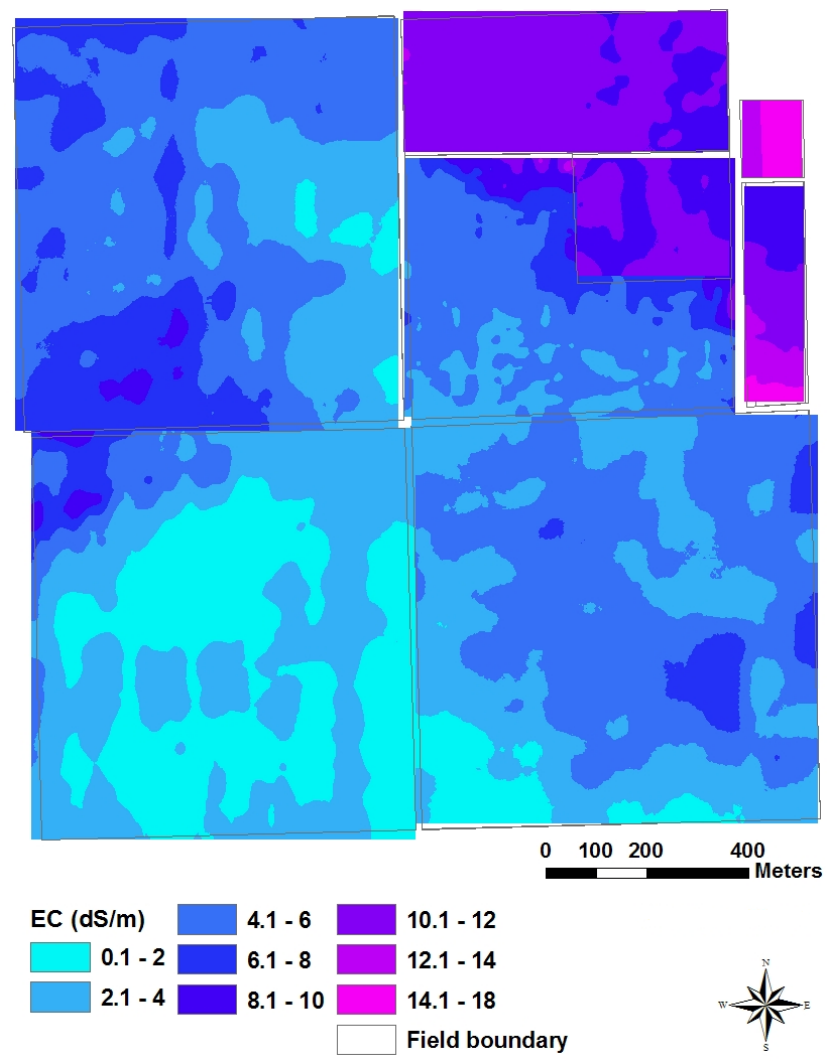

Figure 3: Average salinity distribution $(0-1.5 \mathrm{~m})$ on the surveyed farmland. 


\section{Conclusions}

The purpose of the study was to characterize the distribution and variability of EM induction measurements for canal seepage detection and salinity assessment on irrigated lands. The surveys demonstrated that the EM technique had great potential for quick evaluation of soil properties over large areas and was a costeffective alternative to extensive sampling. Data obtained from the canal surveys can aid in financial decision making by providing information on the extent of canal seepage and need of canal lining. Soil salinity surveys can help in giving recommendations for suitable cropping systems and application of precision farming practices. Overall, this research shows that canal seepage and salinity assessment studies are very valuable tools for improving water management and conservation strategies in salt-affected lands and along canal banks of Central California.

\section{References}

[1] Akbar, S., Use of EM surveys to identify seepage sites in on-farm channel and drains, Irrigation Australia 2000, May 23-25, Melbourne, Australia.

[2] California Department of Water Resources, California Water Plan Update 2005, Bulletin 160-05.

[3] Environmental System Research Institute, ArcGIS, Environmental System Research Institute, Inc.: Cambridge, England, 2005.

[4] Grattan, S. \& Oster, J., Use and reuse of saline-sodic waters for irrigation of crops. Crop Production in Saline Environments, ed. S.S. Goyal, S.K. Sharma, and D.W. Rains, Haworth Press: New York, 2002.

[5] Kaffka, S., Oster, J., \& Corwin, D., Forage production and soil reclamation using saline drainage water. Proc. of CA. alfalfa symposium, pp. 247-253, 2004, http://alfalfa.ucdavis.edu

[6] Klute, A., Methods of Soil Analysis, Part 1 Physical and Mineralogical Methods, ed. American Society of Agronomy: Madison, WI, 1986.

[7] Hendrickx, J., Baerends, B., Raza, Z., Sadig, M. \& Chaudhry, M., Soil salinity assessment by electromagnetic induction of irrigated lands. Soil Science Society of America Journal, 56, pp. 1933-1941, 1992.

[8] Lesch, S., Rhoades, J. \& Corwin, D. ESAP-95 Version 2.01R: User Manual and Tutorial Guide, Research Report No. 146, USDA-ARS, George E. Brown Jr. Salinity Laboratory, Riverside, CA, 2000.

[9] Letey J., Soil Salinity poses challenges for sustainable agriculture and wildlife. California Agriculture, 54(2), 2000.

[10] McKenzie R., George, R., Woods, S., Cannon, M. \& Bennett, D., Use of the electromagnetic-induction meter (EM38) as a tool in managing salinisation. Hydrogeology Journal, 5, pp. 37-50, 1997.

[11] McNeill, J., Electrical conductivity of soils and rocks, Technical Note TN5, ed. Geonics Limited: Mississauga, ON, Canada, 1980.

[12] McNeill, J., Survey interpretation techniques, Technical Note TN-6, ed. Geonics Limited: Mississauga, ON, Canada, 1980. 
[13] Oster, J. \& Grattan, S., Drainage water re-use. Irrigation and Drainage Systems, 16, pp. 297-310, 2002.

[14] Rhoades, J., Salinity: Electrical conductivity and total dissolved salts, Methods of Soil Analysis, Part 3 Chemical Methods ed. D.L. Sparks, American Society of Agronomy: Madison, WI, 1996.

[15] San Joaquin Valley Drainage Implementation Program, Drainage Management in the San Joaquin Valley, A Status Report, 1998.

[16] Slavish, P., Determining $\mathrm{EC}_{\mathrm{a}}$-depth profiles from electromagnetic induction measurements, Australian Journal of Soil Research, 28, pp. 443-452, 1990.

[17] Sudduth, K., Kitchen, N. \& Drummond, S., Soil conductivity sensing on clay pans: comparison of electromagnetic induction and direct methods. Applications of electromagnetic methods: Agriculture, ed. Geonics Limited: Mississauga, ON, Canada, 1999. 